\title{
Facile preparation of nanocrystal-assembled hierarchical mordenite zeolites with remarkable catalytic performance
}

\author{
Yangyang Yuan a,b,c, Linying Wang a,b, Hongchao Liu ${ }^{\mathrm{a}, \mathrm{b}}$, Peng Tian ${ }^{\mathrm{a}, \mathrm{b}, \#}$, Miao Yang a,b, Shutao Xu ${ }^{\mathrm{a}, \mathrm{b}}$, \\ Zhongmin Liu a,b,* \\ a National Engineering Laboratory for Methanol to Olefins, Dalian Institute of Chemical Physics, Chinese Academy of Sciences, Dalian 116023, Liaoning, \\ China \\ b Dalian National Laboratory for Clean Energy, Dalian Institute of Chemical Physics, Chinese Academy of Sciences, Dalian 116023, Liaoning, China \\ c University of Chinese Academy of Sciences, Beijing 100049, China
}

A R T I C L E I N F O

Article history:

Received 16 July 2015

Accepted 18 July 2015

Published 20 November 2015

\section{Keywords:}

Nanocrystal-assembled

Mordenite

Tetraethylammonium hydroxide

Surfactant

Catalytic activity

\begin{abstract}
A B S T R A C T
The present study reports a novel strategy to fabricate nanocrystal-assembled hierarchical MOR zeolites. This is the first demonstration of hierarchical MOR without preferential growth along the $c$-axis, which facilitates mass transfer in the 12-membered ring channels of MOR zeolite for the conversions involving bulky molecules. The facile method involves the combined use of tetraethylammonium hydroxide (TEAOH) and commercial surfactants, in which TEAOH is essential for the construction of nanocrystal assemblies. The surfactant serves as a crystal growth-inhibiting agent to further inhibit nanocrystalline particle growth, resulting in enhanced mesoporosity. The hierarchical MOR assembled particles, constructed of 20-50-nm crystallites, exhibit superior catalytic properties in the alkylation of benzene with benzyl alcohol compared with the control sample, as the hierarchical MOR possesses a larger external surface area and longer $c$-axis dimension. More importantly, the material shows improved activity and stability in the dimethyl ether carbonylation to methyl acetate reaction, which is a novel route to produce ethanol from syngas.
\end{abstract}

(C) 2015, Dalian Institute of Chemical Physics, Chinese Academy of Sciences. Published by Elsevier B.V. All rights reserved.

\section{Introduction}

Zeolites are important heterogeneous catalysts in oil refining and petrochemical industries because of their unique pore structures, large surface area, strong acidity, and excellent hydrothermal stability [1,2]. Mordenite (MOR), one of the most important members in the zeolite family, has exhibited excellent performance in catalysis, such as toluene disproportionation, hydroisomerization, alkylation, dimethylamine synthesis, and dimethyl ether carbonylation [3-5]. The channel system of MOR zeolite consists of a straight 12-membered ring (MR) channel $(0.65 \mathrm{~nm} \times 0.70 \mathrm{~nm})$, a compressed 8-MR channel $(0.26 \mathrm{~nm} \times 0.57 \mathrm{~nm})$ parallel to the $c$-axis, and an additional 8-MR channel ( $0.34 \mathrm{~nm} \times 0.48 \mathrm{~nm})$ along the $b$-axis [6]. However, MOR is generally referred to as a one-dimensional zeolite as the 8-MR channels are too small for most molecules to ingress. This unique pore structure may impose severe diffusion limitations in catalytic processes, leading to underutilization of the active sites and resulting in rapid deactivation, especially for the reactions involving bulky molecules [7-9]. In recent years, the quest for enhancing the catalytic efficiency and prolonging catalyst life has stimulated much research on improv-

\footnotetext{
* Corresponding author. Tel: +86-411-84379998; Fax: +86-411-84379289; E-mail: liuzm@dicp.ac.cn

\# Corresponding author. Tel: +86-411-84379218; Fax: +86-411-84379289; E-mail: tianpeng@dicp.ac.cn

This work was supported by the National Natural Science Foundation of China $(21101150,21476228,21473182)$.

DOI: 10.1016/S1872-2067(15)60960-3 | http://www.sciencedirect.com/science/journal/18722067 | Chin. J. Catal., Vol. 36, No. 11, November 2015
} 
ing the mass transport properties.

Integrating mesopores into the zeolite structures or decreasing the crystal size has proven to be an effective way to overcome the inherent diffusion limitations and improve the catalysis efficiency of zeolites [10-23]. Mesoporous MOR zeolites are hitherto mainly synthesized via a top-down approach through dealumination or sequential dealumination-desilication treatment $[9,24,25]$. A one-step, bottom-up synthesis of mesoporous MOR is highly desirable; however, this remains a challenging task, despite the significant developments in the synthesis of hierarchical zeolites, such as ZSM-5 and beta. Recently, Xiao and co-workers [26] successfully synthesized micro-sized MOR nanofiber bundles when assisted by a self-designed cationic copolymer containing quaternary ammonium groups. Jo and Ryoo et al. [27] reported a zeolite-seeding route to synthesize mesoporous MOR zeolite with nanorod-like morphology by employing organosilane surfactants as a mesopore-generating agent. Very recently, Li and co-workers [28] synthesized H-MOR nanosheet assemblies through a conventional hydrothermal reaction in the absence of templating agents. However, the above-mentioned MOR nanofibers and nanorods show a narrowed $a-b$ cross section, whereas the growth along the $c$-axis direction is less inhibited, suggesting that the 12-MR channels in these hierarchical MOR zeolites have the longest dimension and implying that the mass transport in this direction remains restricted.

Synthesis of zeolite nanocrystals with reduced size in three dimensions decreases the diffusion pathway irrespective of the direction of travel. There are, however, only a few examples reported where nanocrystalline MOR have been effectively synthesized in such a manner. Kubota's group [29] has reported the preparation of MOR nanocrystals of $\sim 80 \mathrm{~nm}$ in diameter using a hydrophobic structure-directing agent, $N, N, N^{\prime}, N^{\prime}$-tetraethylbicyclo[2.2.2] oct-7-ene-2,3:5,6-dipyrrolidinium. In addition, the divalent cation $N, N, N, N^{\prime}, N^{\prime}, N^{\prime}$-hexaethylpentanediammonium was also reported to direct the synthesis of nanoscale MOR [30,31]. Recently, Ryoo et al. [32] developed a multivalent surfactant-capping route to synthesize nanocrystalline zeolites including MOR, FAU, CHA, and MFI. By using a self-designed prolinol derivative surfactant $\mathrm{C}_{18} \mathrm{H}_{37} \mathrm{~N}^{+}(\mathrm{Me})_{2} \mathrm{C}_{6} \mathrm{H}_{12} \mathrm{~N}^{+}\left(\mathrm{CH}_{3}\right)_{2}$ $\mathrm{CH}_{2} \mathrm{C}_{6} \mathrm{H}_{4} \mathrm{CH}_{2} \mathrm{~N}^{+}\left(\mathrm{CH}_{3}\right)\left(\mathrm{C}_{4} \mathrm{H}_{7} \mathrm{CH}_{2} \mathrm{OH}\right)$ as a capping agent, MOR nanocrystals could be readily prepared. They attributed the nanocrystal formation to the multiple valencies on the surfactant and thereby the introduction of a strong binding effect of the surfactant molecules on the substrate surfaces compared with monovalent surfactants.

Herein, we report a facile and direct approach to synthesize nanocrystal-assembled hierarchical MOR zeolites by subjecting the crystallization to relatively low temperatures $\left(130{ }^{\circ} \mathrm{C}\right)$ in the presence of tetraethylammonium hydroxide (TEAOH) and commercial surfactant. The role of TEAOH and surfactants in the generation of the hierarchical assembled structure is investigated in detail and the physicochemical properties of the products are well characterized. The catalytic performance of the hierarchical MOR zeolites is evaluated via the benzylation of benzene with benzyl alcohol (BA) and compared with the control sample and hierarchical MOR having nanosheet-as- sembled morphology with a longer $c$-direction dimension. In addition, the hierarchical zeolite is applied as a catalyst for the dimethyl ether (DME) carbonylation to methyl acetate (MA) reaction, which is a novel route to produce ethanol from syngas.

\section{Experimental}

\subsection{Materials and synthesis}

The chemical reagents used in the experiments included $\mathrm{NaAlO}_{2}$ (54.5\% $\mathrm{Al}_{2} \mathrm{O}_{3}, 40.9 \% \mathrm{Na}_{2} \mathrm{O}$, Tianjin Guangfu Chemical Co.), colloidal silica $\left(30.1 \% \mathrm{SiO}_{2}\right.$, Qingdao Chengyu Chemical Co.), TEAOH (25.0\% in water, Xiamen Pioneer Technology Co., Ltd.), $\mathrm{NaOH}$ (Tianjin Kemiou Chemical Reagent Co.), $\mathrm{C}_{12} \mathrm{H}_{25}$ $\mathrm{N}^{+}\left(\mathrm{CH}_{3}\right)_{2}-\mathrm{C}_{2} \mathrm{H}_{4}-\mathrm{N}^{+}\left(\mathrm{CH}_{3}\right)_{2}-\mathrm{C}_{12} \mathrm{H}_{25} \mathrm{Br}_{2} \quad\left(\mathrm{C}_{12-2-12}\right.$, Henan Titaning Chemical Technology Co.), hexadecyltrimethylammonium bromide (CTAB, Energy Chemical), sodium dodecylbenzenesulphonate (SDBS, Energy Chemical), and Pluronic F-127 $\left(M_{\mathrm{r}}=\right.$ $12600 \mathrm{~g} / \mathrm{mol}$, Sigma). All the above reagents were used without further purification.

A typical synthesis procedure was as follows. $\mathrm{NaOH}$ and surfactant $\left(\mathrm{C}_{12-2-12}\right)$ were dissolved in $\mathrm{H}_{2} \mathrm{O}$ to prepare a clear solution. Thereafter, TEAOH was added to the solution dropwise followed by the addition of $\mathrm{NaAlO}_{2}$. Then, colloidal silica was added to the mixture under vigorous stirring. The final mixture with a composition of $\mathrm{SiO}_{2}: 0.033 \mathrm{Al}_{2} \mathrm{O}_{3}: 0.25 \mathrm{Na}_{2} \mathrm{O}$ :

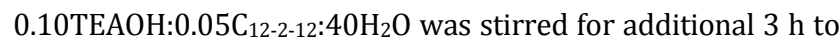
obtain a homogenous gel prior to being transferred into a stainless steel autoclave. The sol-gel was subjected to hydrothermal crystallization at $130{ }^{\circ} \mathrm{C}$ for $5-7 \mathrm{~d}$ and rotated at 60 rpm. The products were recovered by centrifugation, washed with deionized water, dried overnight at $120{ }^{\circ} \mathrm{C}$ and finally calcined at $550{ }^{\circ} \mathrm{C}$ for $5 \mathrm{~h}$ to remove the organic species. The protonated samples were obtained by ion exchange with $\mathrm{NH}_{4} \mathrm{NO}_{3}$ aqueous solution ( $1 \mathrm{~mol} / \mathrm{L}, 1 \mathrm{~g}$ calcined sample in 10 $\mathrm{mL}$ solution) at $80{ }^{\circ} \mathrm{C}$ under stirring. The ion exchange was repeated three times and every ion exchange solution was for 2 h. The samples were recovered by centrifugation, washed with deionized water, and dried at $120{ }^{\circ} \mathrm{C}$ before calcination at 550 ${ }^{\circ} \mathrm{C}$ for $4 \mathrm{~h}$.

\subsection{Characterization}

Powder XRD patterns were recorded on a PANalytical X'Pert PRO X-ray diffractometer with $\mathrm{Cu} K_{\alpha}$ radiation $(\lambda=0.154059$ $\mathrm{nm}$ ) and a scan step width of $0.026^{\circ}$. The chemical composition of the samples was measured using a Philips fluorescence (XRF, Magix-601 X-ray) spectrometer. Morphology was observed using scanning electron microscopy (SEM, SU8020). N2 adsorption-desorption isotherms were obtained on a Micromeritics ASAP 2020 system at $-196^{\circ} \mathrm{C}$. The total surface area was calculated based on the BET model. Micropore volume and micropore surface area were calculated using the $t$-plot method. Pore size distribution of the mesopores was determined by the $\mathrm{BJH}$ method based on the desorption branch of the isotherms.

Solid state NMR experiments were performed on a Varian 
Infinity Plus 400 WB spectrometer with a BBO MAS probe operating at a magnetic field strength of $9.4 \mathrm{~T}$. The resonance frequencies were 104.2 and $79.4 \mathrm{MHz}$ for ${ }^{27} \mathrm{Al}$ and ${ }^{29} \mathrm{Si}$, respectively. Chemical shifts were referenced to $\mathrm{Al}\left(\mathrm{NO}_{3}\right)_{3}(1.0 \mathrm{~mol} / \mathrm{L})$ for ${ }^{27} \mathrm{Al}$ and 2,2-dimethyl-2-silapentane-5-sulfonate sodium salt (DSS) for ${ }^{29} \mathrm{Si}$. The spinning rates of the samples at the magic angle were 4 and $6 \mathrm{kHz}$ for ${ }^{27} \mathrm{Al}$ and ${ }^{29} \mathrm{Si}$, respectively.

Temperature-programmed desorption of ammonia $\left(\mathrm{NH}_{3}-\right.$ TPD) was measured on a Micromeritics 2920 chemical adsorption instrument. After pre-treating the samples at $650^{\circ} \mathrm{C}$ for $1 \mathrm{~h}$ under flowing $\mathrm{He}$, the samples (40-60 mesh, $0.20 \mathrm{~g}$ ) were cooled down to $150{ }^{\circ} \mathrm{C}$ and saturated with $\mathrm{NH}_{3}$ gas. Thereafter, $\mathrm{NH}_{3}$-TPD was performed in a constant flow of $\mathrm{He}(20 \mathrm{~mL} / \mathrm{min})$ from 150 to $650^{\circ} \mathrm{C}$ at a heating rate of $10^{\circ} \mathrm{C} / \mathrm{min}$.

1,3,5-triisopropylbenzene (TIPB) cracking was performed in a fixed-bed reactor at atmospheric pressure. The sample (40-60 mesh, $200 \mathrm{mg}$ ) was loaded into the reactor and dehydrated in $\mathrm{N}_{2}(50 \mathrm{~mL} / \mathrm{min})$ at $500^{\circ} \mathrm{C}$ for $1 \mathrm{~h}$ prior to the reaction. The temperature of the catalyst bed was adjusted to $210{ }^{\circ} \mathrm{C}$ under $\mathrm{N}_{2}$ and fed with vaporized TIPB $\left(85{ }^{\circ} \mathrm{C}\right)$ in $\mathrm{N}_{2}(50$ $\mathrm{mL} / \mathrm{min}$ ). The products were analyzed online by gas chromatography (Agilent 6890) attached to an FID detector using an HP-5 column.

\subsection{Catalytic performance}

DME carbonylation experiments were performed in a continuous flow fixed-bed stainless steel reactor. The catalyst (40-60 mesh, $1.0 \mathrm{~g}$ ) was packed in the reactor and pre-treated under $\mathrm{N}_{2}$ at $500{ }^{\circ} \mathrm{C}$ for $2 \mathrm{~h}$. The catalyst sample was cooled to $200{ }^{\circ} \mathrm{C}$ prior to a reactant gas mixture $(5 \% \mathrm{DME}, 35 \% \mathrm{CO}$, and $60 \% \mathrm{H}_{2}$ ) being introduced into the reactor at a gas hourly space velocity (GHSV) of $1500 \mathrm{~mL} /(\mathrm{g} \cdot \mathrm{h})$. Reaction pressure was 2.0 $\mathrm{MPa}$. The outlet gas was analyzed online using a gas chromatograph (Agilent 7890A) equipped with TCD and FID detectors.

The liquid phase benzylation of benzene with BA was performed in a three-necked round-bottom flask equipped with a reflux condenser and heated in an oil bath at $80{ }^{\circ} \mathrm{C}$ under at- mospheric pressure. In a typical run, $34 \mathrm{~mL}$ of benzene was added with $0.20 \mathrm{~g}$ catalyst, which had been pre-calcined at 500 ${ }^{\circ} \mathrm{C}$ for $4 \mathrm{~h}$. The reaction mixture was stirred at $80^{\circ} \mathrm{C}$ for $30 \mathrm{~min}$, followed by the addition of $2.0 \mathrm{~mL}$ of BA. Liquid samples were withdrawn at intervals. The liquid products were analyzed by gas chromatography using an Agilent 7890 connected to an FID detector using a 50-m HP-5 column. The products were identified by GC-MS analysis.

\section{Results and discussion}

\subsection{Synthesis and characterization of nanocrystal-assembled hierarchical MOR zeolites}

Nanocrystal-assembled hierarchical MOR zeolite (designated as MOR-M) was hydrothermally synthesized in the presence of TEAOH and surfactant $\mathrm{C}_{12-2-12}$ at $130{ }^{\circ} \mathrm{C}$. The reproducible synthetic conditions are summarized in Table 1 . For comparison, the material synthesized under similar conditions in the absence of TEAOH and surfactant is used as a control sample (designated as MOR-C, sample 12 in Table 1). Fig. 1 shows the XRD patterns of MOR-M (sample 1) and MOR-C, which exhibit characteristic diffraction peaks of mordenite structure and confirm the phase purity of the samples. SEM micrographs provide detailed information on the morphology of the samples. As shown in Fig. 2(a), MOR-M consists of near-spherical particles with rough surfaces ranging from 10 to $20 \mu \mathrm{m}$. Increased magnification (Fig. 2(b)) reveals that these aggregates are composed of interconnected nanocrystallites, forming an abundance of interstitial voids, generating a hierarchical structure. Fig. 2(c) displays the TEM micrograph of MOR-M, from which nanocrystals possessing 20 to $50-\mathrm{nm}$ dimensions could be clearly observed. This nanocrystal-assembled morphology is believed to be favorable for catalytic reactions because of the shortened diffusion path. Furthermore, the formation of the nanocrystal assemblies benefits solid-liquid separation after the synthesis. Indeed, the spherical architectures of MOR-M are very stable, preserving their morphology almost intact after

Table 1

Summary of synthetic conditions and textual properties of the MOR products.

\begin{tabular}{|c|c|c|c|c|c|c|c|c|}
\hline \multirow{2}{*}{ Sample } & \multicolumn{2}{|c|}{ Starting gel composition a } & \multirow{2}{*}{$\mathrm{Si} / \mathrm{Al}^{\mathrm{b}}$} & \multicolumn{3}{|c|}{ Surface area ${ }^{c}\left(\mathrm{~m}^{2} / \mathrm{g}\right)$} & \multicolumn{2}{|c|}{ Pore volume ${ }^{\mathrm{c}}\left(\mathrm{cm}^{3} / \mathrm{g}\right)$} \\
\hline & $x$ & $y$ & & $S_{\text {BET }}$ & $S_{\text {micro }}$ & $S_{\text {ext }}$ & $V_{\text {micro }}$ & $V_{\text {total }}$ \\
\hline 1 (MOR-M) & 0.1 & $0.05\left(\mathrm{C}_{12-2-12}\right)$ & 9.1 & 471 & 369 & 102 & 0.17 & 0.62 \\
\hline 2 & 0.1 & 0 & 8.1 & 428 & 352 & 76 & 0.16 & 0.43 \\
\hline 3 & 0 & $0.05\left(\mathrm{C}_{12-2-12}\right)$ & 8.8 & 524 & 302 & 222 & 0.14 & 0.76 \\
\hline 4 & 0.1 & $0.10\left(\mathrm{C}_{12-2-12}\right)$ & - & 477 & 371 & 106 & 0.17 & 0.69 \\
\hline 5 & 0.23 & $0.05\left(\mathrm{C}_{12-2-12}\right)$ & - & 425 & 330 & 95 & 0.16 & 0.71 \\
\hline 6 & 0.1 & 0.02 (CTAB) & - & 493 & 316 & 177 & 0.15 & 0.48 \\
\hline 7 & 0.1 & 0.05 (SDBS) & - & 478 & 343 & 135 & 0.16 & 0.44 \\
\hline 8 & 0.1 & $0.40^{\mathrm{d}}(\mathrm{F}-127)$ & - & 460 & 340 & 120 & 0.16 & 0.40 \\
\hline $9 \mathrm{e}$ & 0 & 0 & - & 390 & 367 & 23 & 0.17 & 0.20 \\
\hline $10^{\mathrm{e}}$ & 0.1 & 0 & - & 399 & 364 & 35 & 0.17 & 0.21 \\
\hline $11 \mathrm{e}$ & 0.1 & $0.05\left(\mathrm{C}_{12-2-12}\right)$ & - & 408 & 370 & 38 & 0.17 & 0.23 \\
\hline 12 (MOR-C) & 0 & 0 & 7.0 & 384 & 344 & 40 & 0.16 & 0.26 \\
\hline
\end{tabular}

a The starting gel composition is $\mathrm{SiO}_{2}: 0.033 \mathrm{Al}_{2} \mathrm{O}_{3}: 0.25 \mathrm{Na}_{2} \mathrm{O}: x$ TEAOH $: y$ surfactant $: 40 \mathrm{H}_{2} \mathrm{O}\left(130^{\circ} \mathrm{C}, 7 \mathrm{~d}\right)$. ${ }^{\mathrm{b}}$ Determined by XRF. c $S_{\mathrm{BET}}$ corresponds to the BET surface area. $S_{\text {micro }}$ and $V_{\text {micro }}$ are micropore surface area and micropore volume determined by the $t$-plot method, respectively. $S_{\text {ext }}=S_{\text {BET }}-$ $S_{\text {micro. }} V_{\text {total }}$ is calculated at $p / p_{0}=0.99$. ${ }^{\mathrm{d}}$ Mass ratio of $\mathrm{F}-127 / \mathrm{SiO}_{2} .{ }^{\mathrm{e}}$ Control experiments conducted at $180{ }^{\circ} \mathrm{C}$ for $20 \mathrm{~h}$. 


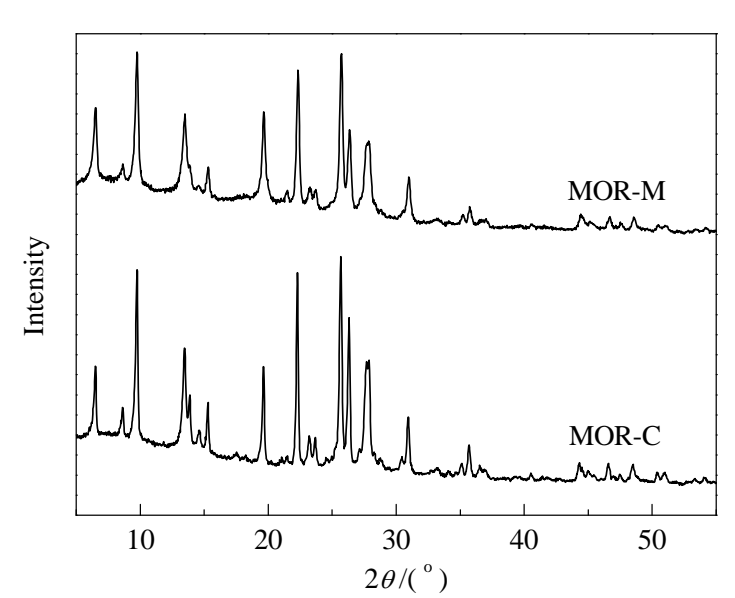

Fig. 1. XRD patterns of the as-synthesized samples MOR-M and MOR-C.
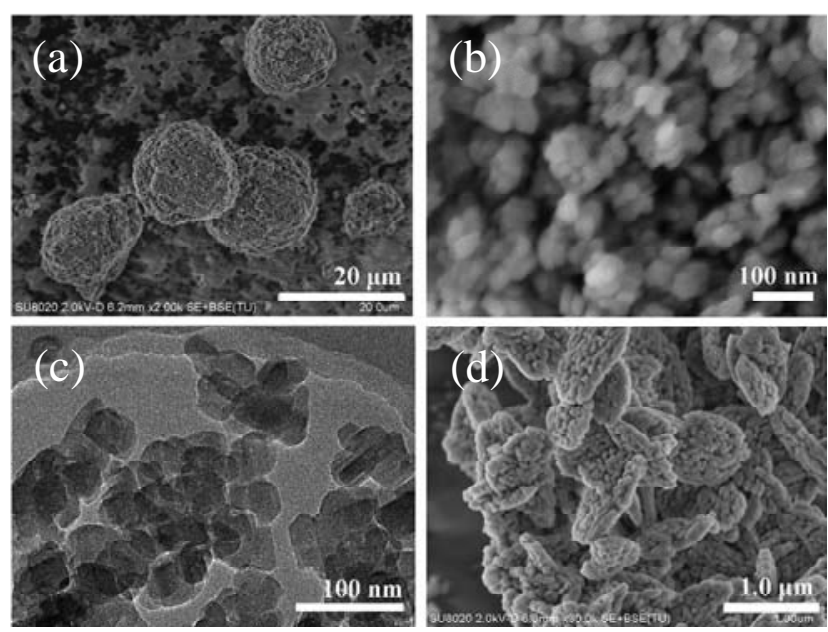

Fig. 2. (a) Low-magnification SEM micrograph of MOR-M; (b) High-magnification SEM micrograph of MOR-M; (c) TEM micrograph of MOR-M; (d) SEM micrograph of MOR-C.

ultrasonic treatment for $30 \mathrm{~min}$. Conversely, the MOR-C sample possesses plate-like morphology consisting of closely packed crystallites (Fig. 2(d)). The distinct morphology between the two samples suggests that the nucleation and growth of MOR crystals are significantly modified by the introduction of TEAOH and $\mathrm{C}_{12-2-12}$.

Fig. 3 presents the $\mathrm{N}_{2}$ sorption isotherms and $\mathrm{BJH}$ pore size distribution curve of the samples. MOR-M exhibits the type IV isotherm with a hysteresis loop at a relative pressure of 0.80-0.95, which demonstrates the existence of intercrystal meso/macroporosity [33]. The corresponding BJH pore size distribution curve derived from the desorption branch indicates that it is rather broad with a mean pore size of $\sim 30 \mathrm{~nm}$. Comparatively, MOR-C presents a type I adsorption curve typical of microporous materials with a small uptake of $\mathrm{N}_{2}$ at high relative pressure. Table 1 shows the textual properties of the samples. In comparison with the control sample MOR-C, MOR-M exhibits a higher BET surface area $\left(471 \mathrm{~m}^{2} / \mathrm{g}\right)$ and larger pore volume $\left(0.62 \mathrm{~cm}^{3} / \mathrm{g}\right)$ owing to the decreased crystal size and the formation of meso- and macropores. It is envisaged that the abundant porosity associated with the nano-sized crystals in MOR-M offers improved ingress of guest molecules
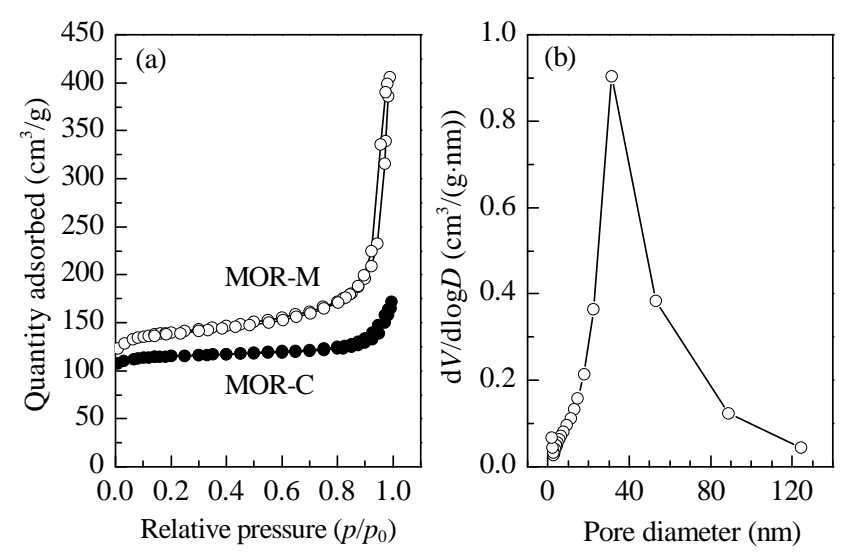

Fig. 3. (a) $\mathrm{N}_{2}$ adsorption-desorption isotherms of MOR-M and MOR-C; (b) The BJH pore size distribution curve of MOR-M calculated from the desorption branch.

into the pores, enhancing diffusion and mass transfer, thus improving the catalytic efficiency.

Solid state ${ }^{27} \mathrm{Al}$ and ${ }^{29} \mathrm{Si}$ MAS NMR spectra were employed to investigate the local atomic coordination environments of MOR-M and MOR-C. As shown in Fig. 4(a), there only exists one sharp peak centered at $\delta=54$ in the ${ }^{27} \mathrm{Al}$ MAS NMR, corresponding to tetrahedral coordinated aluminum species. No peak around $\delta=0$ is observed, which indicates that all the Al atoms were incorporated in the framework. Two major peaks centered at -112 and -105 and a less intense peak at -99 are evident in the ${ }^{29}$ Si MAS NMR spectra, which are ascribed to the $\mathrm{Si}(0 \mathrm{Al}), \mathrm{Si}(1 \mathrm{Al})$, and $\mathrm{Si}(2 \mathrm{Al})$ species, respectively. Notably, the $\mathrm{Si}(0 \mathrm{Al})$ signal in the spectrum of the MOR-M sample is more intense than that of MOR-C, implying a higher $\mathrm{Si} / \mathrm{Al}$ ratio of the former material [34]. The results are consistent with the XRF data-the Si/Al ratio being 9.1 and 7.0 for MOR-M and MOR-C, respectively.

To elucidate the role of TEAOH and $\mathrm{C}_{12-2-12}$ surfactant in the formation of nanocrystal-assembled hierarchical structures, control experiments were conducted with a single TEAOH template, a single $\mathrm{C}_{12-2-12}$ surfactant and different ratios of the two organics while keeping other conditions unchanged. The experimental conditions and textual properties of the products
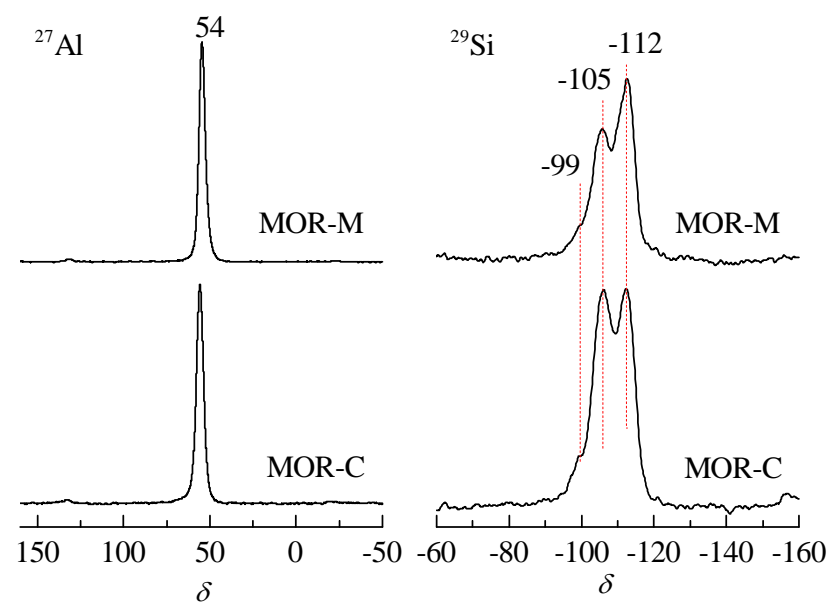

Fig. 4. ${ }^{27} \mathrm{Al}$ and ${ }^{29} \mathrm{Si}$ MAS NMR spectra of MOR-M and MOR-C. 
are listed in Table 1. Fig. 5 illustrates the SEM micrographs of the samples. Sample 2 synthesized with a $\mathrm{TEAOH} / \mathrm{SiO}_{2}$ ratio of 0.1 shows an aggregated morphology similar to MOR-M, implying that nanocrystal-assembled mordenite could be obtained with low concentrations of TEAOH at $130{ }^{\circ} \mathrm{C}$. Thermal analysis confirms the existence of $\mathrm{TEA}^{+}$in the product with a mass loss of $8.2 \%$ in the temperature range of $300-700{ }^{\circ} \mathrm{C}$. The surface area $\left(428 \mathrm{~m}^{2} / \mathrm{g}\right)$ and pore volume $\left(0.43 \mathrm{~cm}^{3} / \mathrm{g}\right)$ of sample 2 are smaller than that of MOR-M, possibly owing to larger nanocrystal sizes $(50-70 \mathrm{~nm})$. Sample 3 presents variation in its morphology as nanosheet assemblies are formed upon the addition of $\mathrm{C}_{12-2-12}$ surfactant only in the initial gel. From Fig. $5(\mathrm{~b})$, it can be seen that each individual nanosheet has a thickness of $\sim 30 \mathrm{~nm}$ and a length of $\sim 500 \mathrm{~nm}$. The corresponding FFT diffractograms reveal that the longest dimension of the nanosheet runs along the $c$-axis direction. This is expected considering that multivalent surfactants could serve as a capping agent to direct the formation of MOR nanorods and nanosheets (having a preferential growth along the $c$-direction) as reported by Ryoo and co-workers [32]. The nanosheet assembly exhibits much larger external surface area and higher mesopore volume than MOR-M and MOR-C. Further increasing the concentration
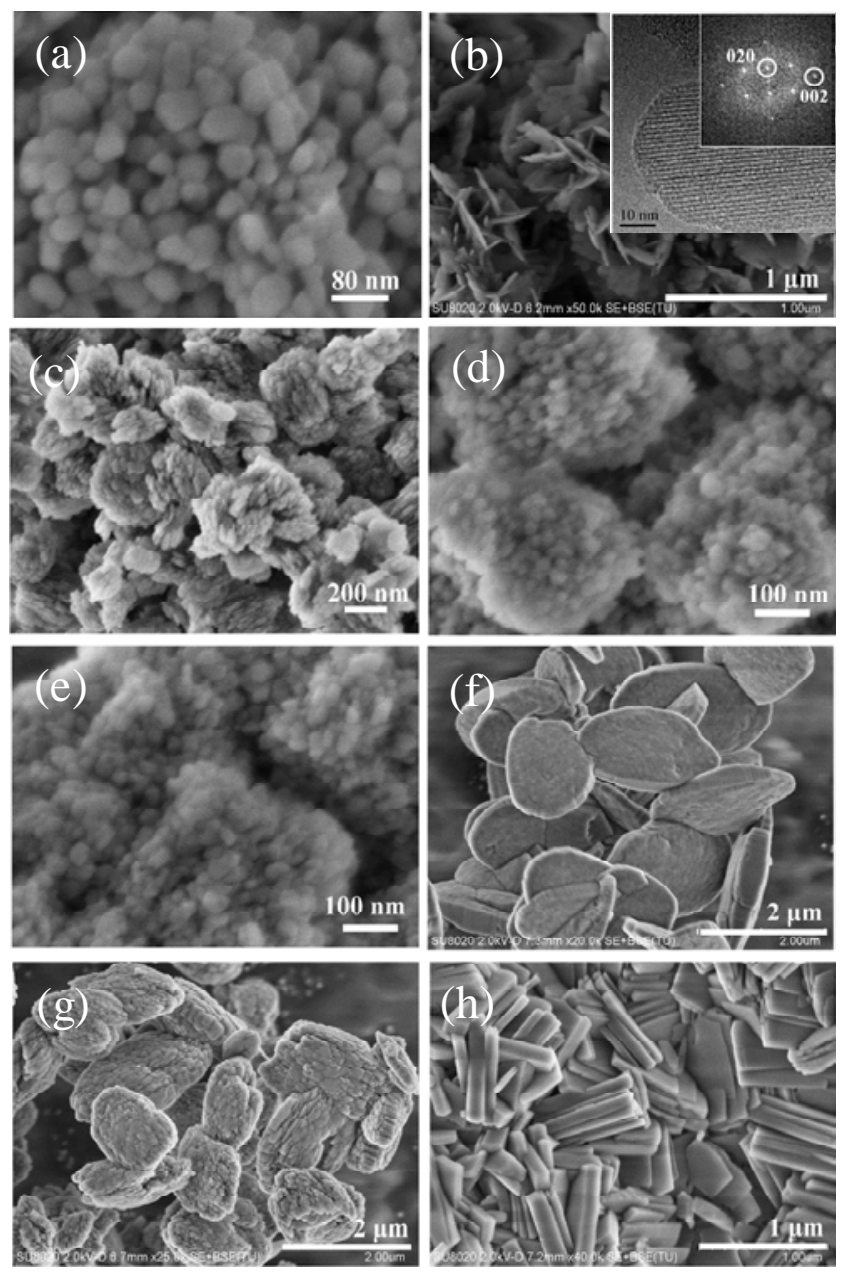

Fig. 5. SEM micrographs of sample 2 (a), 3 (b), 6 (c), 7 (d), 8 (e), 9 (f), 10 $(\mathrm{g})$, and $11(\mathrm{~h})$ in Table 1. The inset in (b) shows the HRTEM micrograph and the corresponding selected FFT diffractogram viewed along the (100) axis. of $\mathrm{C}_{12-2-12}$ or TEAOH in the gel has little effect on enhancing the mesoporosity of the products (samples 4 and 5). It is thus concluded that the smaller molecule TEAOH alone can decrease the MOR crystal size and induce hierarchical structure formation. The addition of the surfactant to the sol-gel is not essential for the formation of nanocrystal assemblies; however, the combined presence of TEAOH further inhibits crystal growth improving the external surface area. TEAOH is generally used in the synthesis of high-silica MOR zeolites [35,36], while the use of TEAOH to form hierarchical MOR remains less explored. Herein, it is suggested that TEAOH functions as a micropore-directing agent, which induces significantly more nuclei, leading to smaller crystal sizes. Additionally, TEA+ has been reported to adsorb on the crystal surface [37,38], preventing excessive interconnection among nanocrystallites, prompting the formation of the final morphology.

Interestingly, the growth inhibition effect of the surfactant is not limited to $\mathrm{C}_{12-2-12}$. By applying the present synthetic strategy, nanocrystal-assembled MOR could be hydrothermally synthesized with various conventional surfactants, such as CTAB, SDBS, and F-127 (samples 6-8 in Table 1). All three samples present irregular micrometer-sized morphology composed of very small nanoparticles (Fig. 5). The type IV isotherms associated with the BJH pore size distribution of the samples are given in Fig. 6, which clearly indicate the presence of mesopores in the structures. Comparatively, the single use of each surfactant in the absence of TEAOH could not produce the nanocrystal-assembled hierarchical structure. This confirms again that the presence of TEAOH is vital to the generation of the nanocrystal assembly, whereas the surfactant serves more as a growth-inhibiting agent possibly through interaction with the negatively charged crystal surface [39] or the $\mathrm{TEA}^{+}$adsorbed on the surface $[37,38]$.

Further samples were synthesized at higher temperatures $\left(180^{\circ} \mathrm{C}\right)$ to investigate the effect of crystal growth behavior as a function of crystallization temperature (samples 9-11 in Table 1). All products exhibit distinct morphology from the corresponding samples synthesized at $130{ }^{\circ} \mathrm{C}$ possessing the same sol-gel compositions. Sample 9 synthesized in the absence of TEAOH and $\mathrm{C}_{12-2-12}$ displays elliptic micrometer-sized mor-
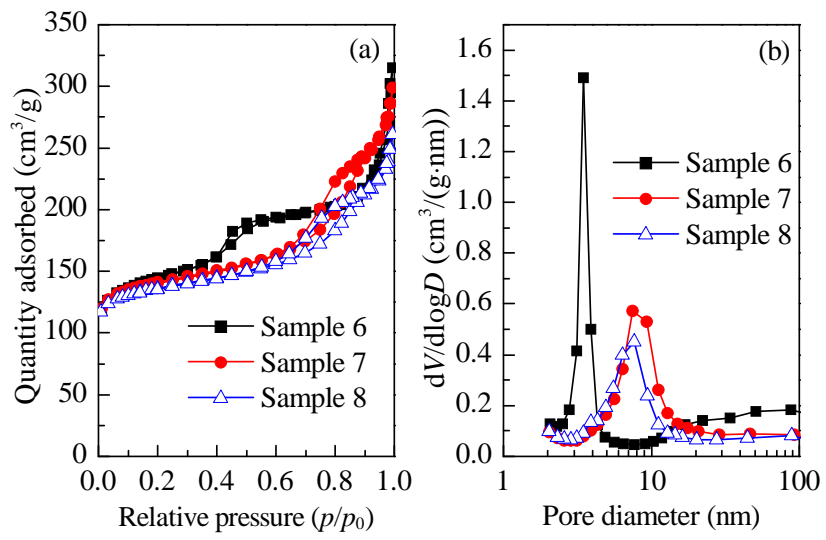

Fig. 6. (a) $\mathrm{N}_{2}$ adsorption-desorption isotherms and (b) the pore size distribution curves of the samples. The pore size distributions are derived from the desorption branches of the isotherms. 
phology with smooth surfaces. After the introduction of TEAOH, the product (sample 10) possesses rough surfaces composed of closely packed nanoscale particles. A low external surface area of $35 \mathrm{~m}^{2} / \mathrm{g}$ and a dramatically reduced pore volume of $0.21 \mathrm{~cm}^{3} / \mathrm{g}$ are observed, indicating that the adsorption of $\mathrm{TEA}^{+}$on the crystal surface and its inhibition on crystal intergrowth may be significantly weakened at higher temperatures. In addition, sample 11 synthesized with the addition of both TEAOH and C12-2-12 displays well-defined morphology with overlapped slabs on the particle surface. Here the external surface area decreases to $38 \mathrm{~m}^{2} / \mathrm{g}$. These results demonstrate that the morphology and porosity of the products are sensitive to the crystallization temperature with lower temperatures favoring the formation of the present hierarchical structure $[40,41]$.

\subsection{Acidity and catalytic performance of MOR-M}

\subsubsection{Acidity of the zeolites}

$\mathrm{NH}_{3}$-TPD experiments were performed to investigate the acid properties of the samples. Fig. 7 presents the $\mathrm{NH}_{3}$-TPD profiles of MOR-M and MOR-C. Both data sets exhibit two peaks assigned to weak and strong acid sites, respectively. The stronger acid strength associated with the MOR-M sample may relate to variation in framework $\mathrm{Al}$ distribution resulting from the use of the TEAOH template [42]. In addition, MOR-M has a lower acid concentration compared with the control sample, owing to its slightly higher $\mathrm{Si} / \mathrm{Al}$ ratio.

The acid sites located on the external surface of the samples were further evaluated by the TIPB cracking reaction. As the TIPB molecule possesses a kinetic diameter of $0.95 \mathrm{~nm}$, ingress to the 12-MR channel of the mordenite zeolite is prevented and thus the first-order cracking of TIPB selectively occurs on the external acid sites [43]. Fig. 8 illustrates the conversion of TIPB as a function of time on stream. MOR-M shows a high initial conversion of $77.5 \%$, whereas only $29.1 \%$ conversion is obtained on MOR-C. After the reaction had progressed for $3 \mathrm{~h}$, a clear decrease of the TIPB conversion occurs over both catalysts. The conversion on MOR-M drops to $34.4 \%$, maintaining $44 \%$ of the initial conversion. However, the MOR-C standard after $3 \mathrm{~h}$ on stream gives only $6.8 \%$ TIPB conversion, corresponding to $23.3 \%$ of the fresh conversion value. The superior

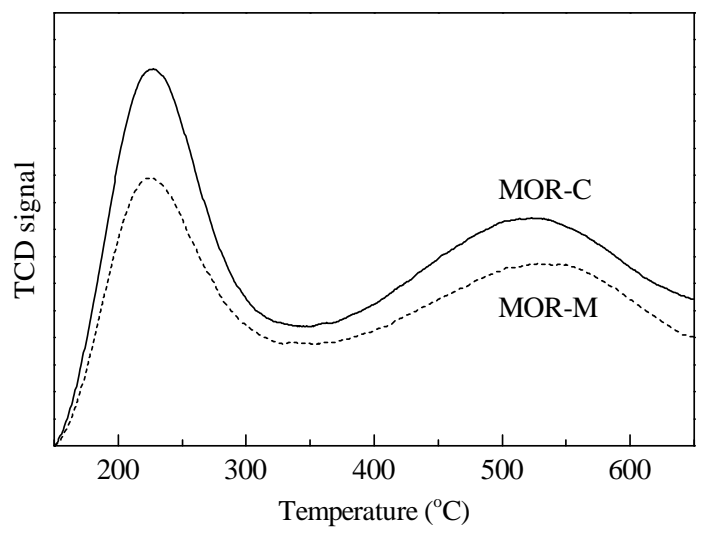

Fig. 7. $\mathrm{NH}_{3}-\mathrm{TPD}$ curves of the protonated MOR-M and MOR-C samples.

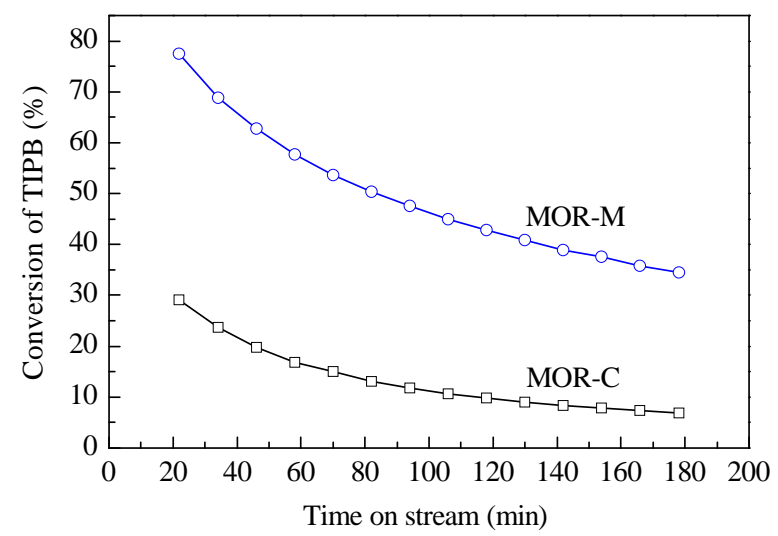

Fig. 8. Catalytic cracking conversion of 1,3,5-triisopropylbenzene (TIPB) over protonated MOR-M and MOR-C catalysts. Reaction conditions: vaporized TIPB in nitrogen $\left(50 \mathrm{~mL} / \mathrm{min}, 85^{\circ} \mathrm{C}\right)$ as feed, $210{ }^{\circ} \mathrm{C}, 0.20 \mathrm{~g}$ catalyst.

catalytic activity of MOR-M and the ability to resist deactivation in TIPB cracking when compared with the conventional standard confirms the higher concentration of acid sites located on the external surface of the sample.

\subsubsection{Catalytic performance of MOR-M in the benzylation of} benzene with benzyl alcohol (BA)

The liquid phase benzylation of benzene with BA was performed to investigate the catalytic properties of the samples in the acid-catalyzed reactions involving bulky molecules. As presented in Fig. 9, MOR-M exhibits significantly improved catalytic activity than the control sample, MOR-C, during the entire reaction time. The BA conversion is $2.8 \%$ at $t=0.5 \mathrm{~h}$ and gradually rises to $12.0 \%$ with reaction time, prolonged to $4 \mathrm{~h}$, when using MOR-C as the catalyst. Comparatively, the conversion of BA over the hierarchical MOR-M increases rapidly as a function

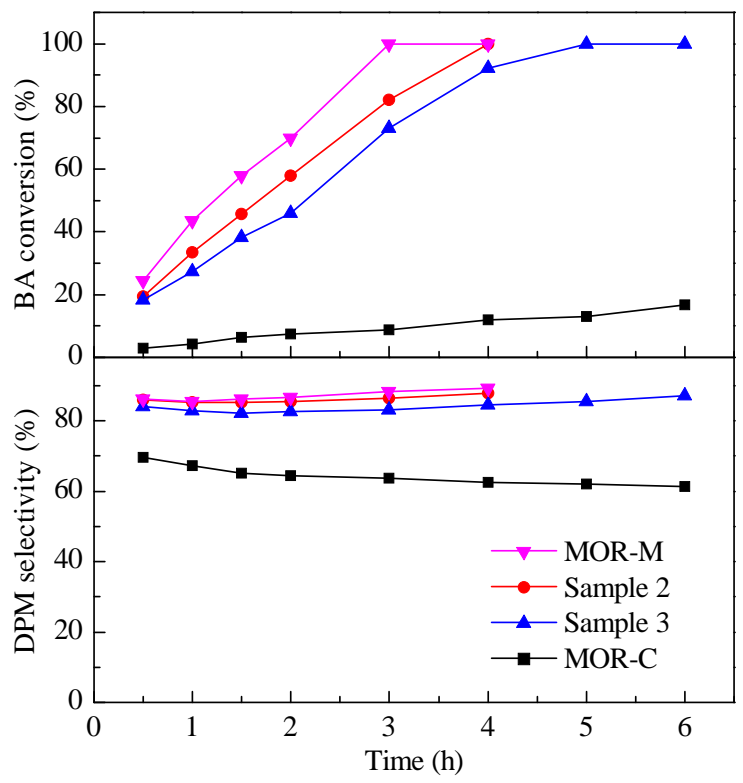

Fig. 9. A comparison of the catalytic performance of the protonated samples in the benzylation of benzene with BA. Reaction conditions: 1.0 $\mathrm{mL}$ BA, $34 \mathrm{~mL}$ benzene, $0.20 \mathrm{~g}$ catalyst, $80^{\circ} \mathrm{C}$. 
of time and a complete conversion of $100 \%$ is readily achieved at a reaction time of $3 \mathrm{~h}$, showing the enhanced catalytic efficiency over the conventional standard. Moreover, the selectivity of the target product diphenylmethane (DPM) over MOR-M reaches close to $90 \%, 15 \%-30 \%$ higher than the corresponding MOR-C sample throughout the reaction. In principle, the acid sites responsible to polarize BA to produce an electrophilic intermediate play a crucial role in the present reaction $[9,44]$. However, the observed catalytic performance does not correlate well to the acid properties of the catalysts. Considering that both MOR-M and MOR-C possess similar acid strength, and the former possesses a lower acid concentration than the latter, the improved activity and selectivity than MOR-C is thought to be attributed to the shortened diffusion path together with a higher concentration of acid sites on the external surface.

To further demonstrate the excellent catalytic performance of the present nanocrystal-assembled hierarchical MOR-M, samples 2 and 3 were also tested as catalysts and the results are given in Fig. 9. Sample 2, synthesized from a TEAOH/SiO ratio of 0.1 , displays good catalytic activity, being only slightly lower than MOR-M. This is somewhat expected as sample 2 has similar morphology, but with a smaller external surface area and pore volume compared with MOR-M. A further reduction in activity is observed over sample 3 , which converts less BA than both MOR-M and sample 2 until a conversion of $100 \%$ is reached at $t=5 \mathrm{~h}$. Here, the diffusion limitation is believed to be the main reason for the inferior catalytic activity of sample 3 with the highest external surface area and largest pore volume among the samples. The nanosheet-assembled morphology of sample 3 , in which the 12 -MR channels run parallel to the longest dimension, would result in a relatively slow diffusion and thus slow down the reaction inside the channels. These results clearly demonstrate that decreasing the crystal size of MOR zeolites, especially in the $c$-direction, effectively enhances mass transfer in the 12-MR channels, producing superior catalytic activity as observed with MOR-M.

\subsubsection{Catalytic performance of MOR-C in the carbonylation of dimethyl ether (DME) to methyl acetate (MA)}

The carbonylation of DME to MA is a key step to produce ethanol from syngas. Mordenite zeolite has proven to be the most promising catalyst with high activity and MA selectivity [45]. According to the literature, the target reaction exclusively proceeds in the 8-MR side-pockets of MOR zeolite, whereas the acid sites in the 12-MR main channels prompt the occurrence of side reactions resulting in coke formation and fast deactivation $[46,47]$. It is expected that the shortened diffusion path in MOR-M facilitates mass transfer and enhances catalyst activity and stability.

Pre-adsorption of pyridine on the acid sites located in the straight channels has been verified to be an effective way to retard the catalyst deactivation and significantly prolong the lifetime [46]. However, here, the catalytic reactions are conducted without pyridine pre-adsorption, to clearly compare the catalytic performance of the hierarchical MOR-M and MOR-C. Fig. 10 presents the DME conversion and MA selectivity as a function of time on stream over the samples. It is evident that

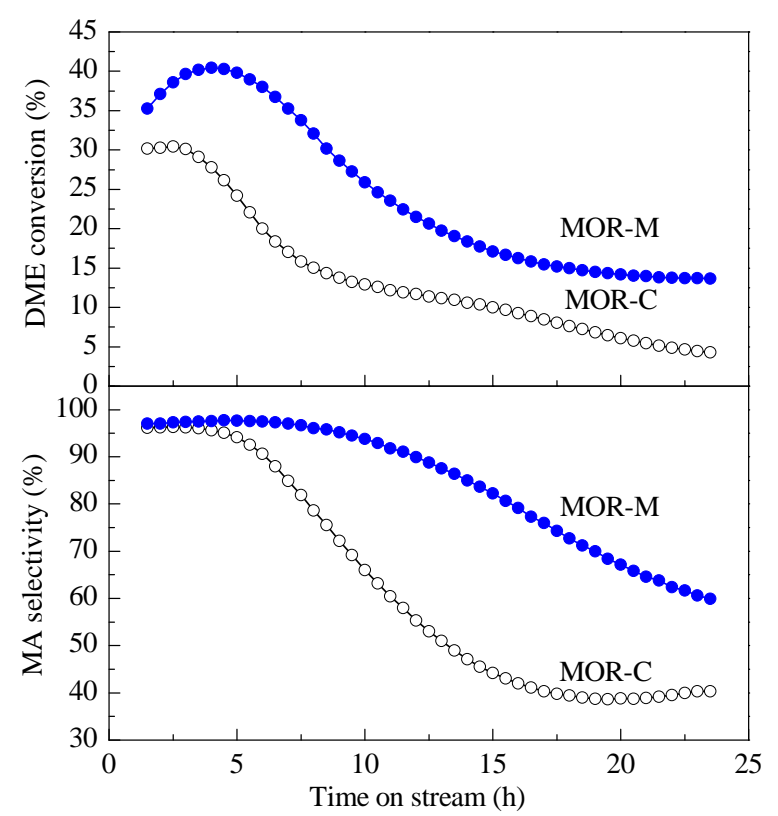

Fig. 10. DME conversion and MA selectivity of DME carbonylation over protonated MOR-M and MOR-C catalysts. Reaction conditions: $200{ }^{\circ} \mathrm{C}$, 2.0 MPa, DME/CO/H2 = 5/35/60 (vol\%), GHSV = $1500 \mathrm{~mL} /(\mathrm{g} \cdot \mathrm{h}$ ).

MOR-M exhibits significantly improved activity compared with MOR-C during the entire run time. An induction period of about $4 \mathrm{~h}$ is observed on MOR-M, during which the conversion of DME increases from $35.2 \%$ at $1.5 \mathrm{~h}$ to $40.4 \%$ at $4 \mathrm{~h}$. Thereafter, the conversion of DME gradually drops to $13.6 \%$ at $23.5 \mathrm{~h}$, maintaining $33.6 \%$ conversion. For MOR-C standard material, the conversion of DME is relatively stable during the first $3 \mathrm{~h}$ $(\sim 30 \%)$, which then finally decreases to $4.2 \%$ after a reaction time of $23.5 \mathrm{~h}$. This value amounts to only $13.9 \%$ of the initial conversion, implying a faster deactivation over MOR-C than on the hierarchical sample. The improved activity and anti-deactivation ability of MOR-M should arise from the reduced diffusion limitations and the abundant porosity, which leads to a more efficient utilization of the acid sites in the side-pocket 8-MR channels [31].

The selectivity of MA over MOR-M and MOR-C also shows differences, though both samples display a similar trend following the decrease of DME conversion. MOR-M is able to sustain a high level of MA selectivity over a longer period of time than on MOR-C. The selectivity drops to $59.8 \%$ on the hierarchical zeolite at $23.5 \mathrm{~h}$, whereas only a selectivity of $40.3 \%$ on the conventional zeolite is observed. The results indicate that the side reactions, which occur in the 12-MR channels, are likely to be suppressed by the improved mass transport of the product. The coke content on the catalysts after $23.5 \mathrm{~h}$ of reaction was further detected by TG analysis. Three peaks are observed in the DTG curves (Fig. 11), corresponding to physisorbed water, soft cokes, and hard cokes, respectively [48]. The total coke amount was $6.5 \mathrm{wt} \%$ for the deactivated MOR-M, while a much higher coke deposition was found on MOR-C (11.3 wt\%). This implies that the coke formation is much slower on MOR-M, further confirming the advantage of the shortened diffusion length. 


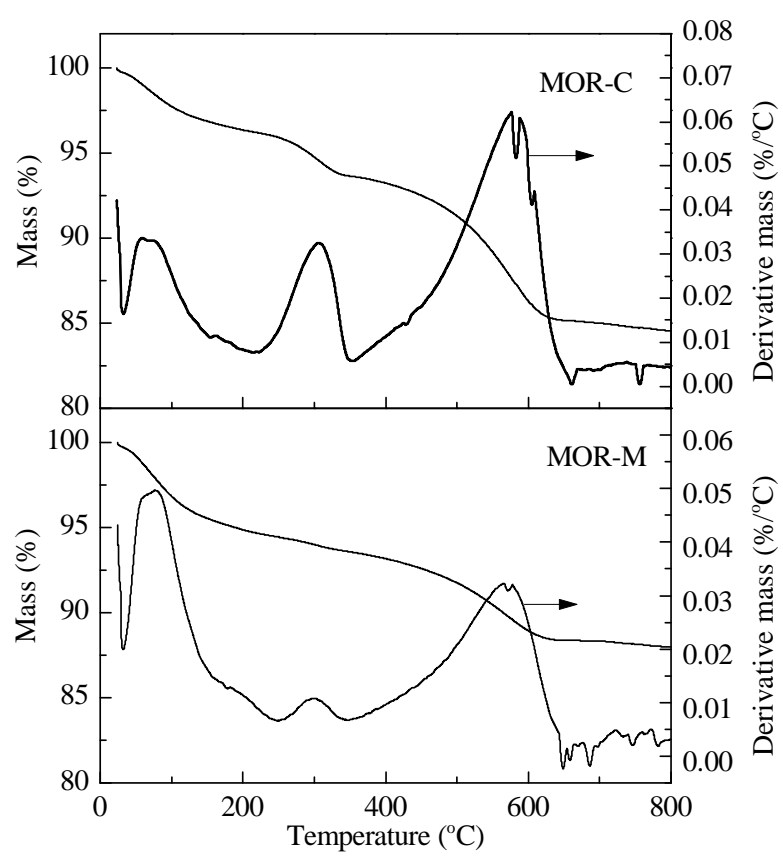

Fig. 11. TG-DTG curves of the coked catalysts after $23.5 \mathrm{~h}$ of DME carbonylation reaction.

\section{Conclusions}

We developed a facile synthetic strategy to fabricate hierarchical MOR zeolites that results in nanocrystal-assembled morphology composed of 20-50-nm crystallites dramatically reducing mass transport limitation. Detailed investigation shows that the use of TEAOH itself at lower crystallization temperatures could decrease the crystal size and generate hierarchical structures constructed by the interconnection of nanocrystals. The introduction of the cationic $\mathrm{C}_{12-2-12}$ surfactant in the TEAOH-containing sol-gel further reduces the crystal size and improves the porosity of the products. However, the surfactant used in the present system is not limited to $\mathrm{C}_{12-2-12}$. Several commercial surfactants including CTAB, anionic SDBS and neutral F-127 also exhibit the ability to decrease the nanocrystal size when used in conjunction with TEAOH. More importantly, the nanocrystal assemblies show much higher catalytic activity in benzylation of benzene with BA in comparison with the control sample, and the hierarchical MOR possesses a longer $c$-axis dimension and larger external surface area. The results demonstrate that the decreased crystal size of the MOR zeolite, especially in the $c$-direction, could effectively prompt mass transport in the 12-MR channels, leading to superior catalytic efficiency. In addition, the material also displays enhanced activity and anti-deactivation behavior in the DME carbonylation reaction. This attractive approach, employing commercially available templates and surfactants, provides an effective and viable way to synthesize MOR nanocrystal assemblies with excellent catalytic performance.

\section{References}

[1] Corma A. Chem Rev, 1997, 97: 2373

[2] Weitkamp J. Solid State Ionics, 2000, 131: 175

[3] Cheung P, Bhan A, Sunley G J, Law D J, Iglesia E. J Catal, 2007, 245: 110

[4] Tromp M, van Bokhoven J A, Oostenbrink M T G, Bitter J H, de Jong K P, Koningsberger D C. J Catal, 2000, 190: 209

[5] Becker K A, Karge H G, Streubel W D. J Catal, 1973, 28: 403

[6] Meier W M. Z Kristall, 1961, 115: 439

[7] Boronat M, Martínez C, Corma A. Phys Chem Chem Phys, 2011, 13: 2603

[8] Ordomsky V V, Ivanova I I, Knyazeva E E, Yuschenko V V, Zaikovskii V I.J Catal, 2012, 295: 207

[9] Leng K Y, Wang Y, Hou C M, Lancelot C, Lamonier C, Rives A, Sun Y Y.J Catal, 2013, 306: 100

[10] Yang M, Tian P, Wang C, Yuan Y Y, Yang Y, Xu S T, He Y L, Liu Z M.

\section{Graphical Abstract}

Chin. J. Catal., 2015, 36: 1910-1919 doi: 10.1016/S1872-2067(15)60519-6

Facile preparation of nanocrystal-assembled hierarchical mordenite zeolites with remarkable catalytic performance

Yangyang Yuan, Linying Wang, Hongchao Liu, Peng Tian*, Miao Yang, Shutao Xu, Zhongmin Liu*

Dalian Institute of Chemical Physics, Chinese Academy of Sciences; University of Chinese Academy of Sciences
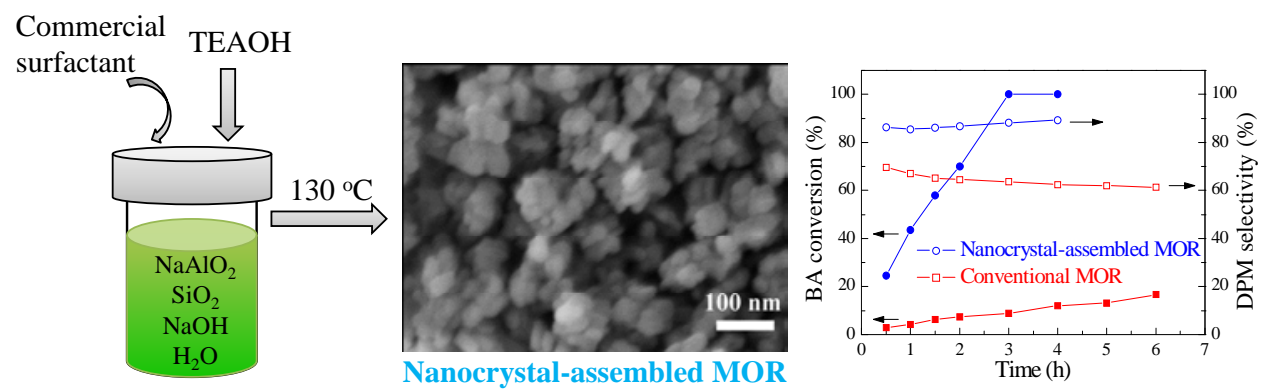

A facile synthetic strategy is developed to fabricate hierarchical mordenite (MOR) zeolites assembled by 20-50-nm crystallites, which exhibit greatly enhanced activity, selectivity, and stability in catalytic reactions. 
Chem Commun, 2014, 50: 1845

[11] Tosheva L, Valtchev V P. Chem Mater, 2005, 17: 2494

[12] Holm M S, Taarning E, Egeblad K, Christensen C H. Catal Today, 2011, 168: 3

[13] Chen L H, Li X Y, Rooke J C, Zhang Y H, Yang X Y, Tang Y, Xiao F S, Su B L.J Mater Chem, 2012, 22: 17381

[14] Ivanova I I, Knyazeva E E. Chem Soc Rev, 2013, 42: 3671

[15] Möller K, Bein T. Chem Soc Rev, 2013, 42: 3689

[16] Serrano D P, Escola J M, Pizarro P. Chem Soc Rev, 2013, 42: 4004

[17] Verboekend D, Milina M, Mitchell S, Pérez-Ramírez J. Cryst Growth Des, 2013, 13: 5025

[18] Li K H, Valla J, Garcia-Martinez J. ChemCatChem, 2014, 6: 46

[19] Yuan Y Y, Tian P, Yang M, Fan D, Wang L Y, Xu S T, Wang C, Wang D H, Yang Y, Liu Z M. RSC Adv, 2015, 5: 9852

[20] Wang Q Y, Wei Y X, Xu S T, Zhang M Z, Meng S H, Fan D, Qi Y, Li J Z Yu Z X, Yuan C Y, He Y L, Xu S L, Chen J R, Wang J B, Su B L, Liu Z M. Chin J Catal (王全义, 魏迎旭, 徐舒涛, 张默之, 孟霜鹤, 㚞栋, 齐 越, 李金哲, 于政锡, 袁翠峪, 何艳丽, 徐庶亮, 陈景润, 王金棒, 苏宝连, 刘中民. 催化学报), 2014, 35: 1727

[21] Tao H X, Yang H, Zhang Y H, Ren J W, Liu X H, Wang Y Q, Lu G Z. J Mater Chem A, 2013, 1: 13821

[22] Li X Y, Sun M H, Rooke J C, Chen L H, Su B L. Chin J Catal (李小云, 孙明慧, Rooke J C, 陈丽华, 苏宝连. 催化学报), 2013, 34: 22

[23] Yang J H, Chu J, Wang J Q, Yin D H, Lu J M, Zhang Y. Chin J Catal (杨 建华, 初筠, 王金渠, 殷德宏, 鲁金明, 张艳. 催化学报), 2014, 35: 49

[24] Huang S J, Liu X H, Yu L L, Miao S, Liu Z N, Zhang S, Xie S J, Xu L Y. Microporous Mesoporous Mater, 2014, 191: 18

[25] Góra-Marek K, Tarach K, Tekla J, Olejniczak Z, Kuśtrowski P, Liu L C, Martinez-Triguero J, Rey F. J Phy Chem C, 2014, 118: 28043

[26] Tang T D, Zhang L, Fu W Q, Ma Y L, Xu J, Jiang J, Fang G, Y Xiao F S.J Am Chem Soc, 2013, 135: 11437

[27] Kim J, Jo C, Lee S, Ryoo R. J Mater Chem A, 2014, 2: 11905

[28] Liu Y H, Zhao N, Xian H, Cheng Q P, Tan Y S, Tsubaki N, Li X G. ACS Appl Mater Interfaces, 2015, 7: 8398

[29] Inagaki S, Watanabe Y, Nishita Y, Kubota Y. Chem Lett, 2013, 42: 186
[30] Lee S H, Lee D K, Shin C H, Paik W C, Lee W M, Hong S B. J Catal, 2000, 196: 158

[31] Xue H F, Huang X M, Ditzel E, Zhan E S, Ma M, Shen W J. Ind Eng Chem Res, 2013, 52: 11510

[32] Jo C, Jung J, Shin H S, Kim J, Ryoo R. Angew Chem Int Ed, 2013, 52: 10014

[33] Liu Y, Zhou X Z, Pang X M, Jin Y Y, Meng X J, Zheng X H, Gao X H, Xiao F S. ChemCatChem, 2013, 5: 1517

[34] Oumi Y, Kakinaga Y, Kodaira T, Teranishi T, Sano T. J Mater Chem, 2003, 13: 181

[35] Lu B W, Tsuda T, Oumi Y, Itabashi K, Sano T. Microporous Mesoporous Mater, 2004, 76: 1

[36] Lv A L, Xu H, Wu H H, Liu Y M, Wu P. Microporous Mesoporous Mater, 2011, 145: 80

[37] Li F, Yang L L, Xu G, Huang X Q, Yang X, Wei X, Ren Z H, Shen G, Han G R.J Alloys Compd, 2013, 577: 663

[38] Jelfs K E, Slater B, Lewis D W, Willock D J. Stud Surf Sci Catal, 2007, 170: 1685

[39] Che S N, Liu Z, Ohsuna T, Sakamoto K, Terasaki O, Tatsumi T. Nature, 2004, 429: 281

[40] Valtchev V P, Tosheva L, Bozhilov K N. Langmuir, 2005, 21: 10724

[41] Larsen S C. J Phy Chem C, 2007, 111: 18464

[42] Dědeček J, Sobalík Z, Wichterlová B. Catal Rev-Sci Eng, 2012, 54: 135

[43] Tarach K, Góra-Marek K, Tekla J, Brylewska K, Datka J, Mlekodaj K, Makowski W, López M C I, Triguero J M, Rey F. J Catal, 2014, 312 : 46

[44] Coq B, Gourves V, Figuéras F. Appl Catal A, 1993, 100: 69

[45] Cheung P, Bhan A, Sunley G J, Iglesia E. Angew Chem Int Ed, 2006, 45: 1617

[46] Liu J L, Xue H F, Huang X M, Wu P H, Huang S J, Liu S B, Shen W J. Chin J Catal (刘俊龙, 薛会福, 黄秀敏, 吴培豪, 黄信炅, 刘尚斌, 申文杰. 催化学报), 2010, 31: 729

[47] Boronat M, Martínez-Sánchez C, Law D, Corma A. J Am Chem Soc, 2008, 130: 16316

[48] Zhou H, Zhu W L, Shi L, Liu H C, Liu S P, Xu S T, Ni Y M, Liu Y, Li L L, Liu Z M. Catal Sci Technol, 2015, 5: 1961

\title{
纳米晶自组装多级孔丝光沸石合成及其优异的催化性能
}

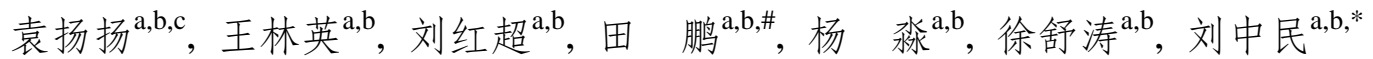 \\ ${ }^{\mathrm{a}}$ 中国科学院大连化学物理研究所甲醇制烯烃国家工程实验室, 辽宁大连 116023 \\ b 中国科学院大连化学物理研究所洁净能源国家实验室(筹), 辽宁大连116023 \\ c中国科学院大学, 北京100049
}

摘要: 由于具有独特的孔道结构、高的热稳定性及适宜的酸性, 丝光沸石(MOR)被广泛应用于正构烷烃异构化、二甲苯异构化、 烷基化、甲苯歧化与烷基芳烃之间的烷基转移以及二甲醚羭基化反应中. 但是其单一的微孔孔道结构在催化反应中带来严重的 扩散限制, 导致微孔内部活性位点利用率低和容易积碳失活等问题, 同时也限制了MOR在大分子催化反应中的应用. 在分子篮中 引入介孔或减小晶粒尺寸是克服扩散限制的有效方法, 也成为目前分子篮领域的研究热点. 早期的研究中主要通过水蒸气处理、 酸处理或碱处理等方法来制备多级孔MOR. 但是, 对于富铝的MOR, 通常需要通过多步处理才能引入介孔. 一步法直接制备多级 孔MOR是目前的研究热点和难点. 虽然文献报道可以采用自制的具有随机分子量分布的阳离子聚合物为模板剂和双亲有机硅表 面活性剂OS-12制备多级孔MOR, 但是合成的多级孔MOR为具有较窄 $a-b$ 截面的纳米纤维或纳米棒状MOR, 其12元环主孔道中的 扩散限制没有得到有效改善. 研究者采用 $N, N, N^{\prime}, N^{\prime}$-四乙基-外,外-二环 [2.2.2]辛-7-烯-2,3:5,6-联四氢吡咯二碘铵盐和 $N, N, N, N^{\prime}, N^{\prime}, N^{\prime}$ - 六乙基-1,5-戊二胺阳离子为结构导向剂或者多季铵盐表面活性剂 $\mathrm{C}_{18} \mathrm{H}_{37} \mathrm{~N}^{+}(\mathrm{Me})_{2} \mathrm{C}_{6} \mathrm{H}_{12} \mathrm{~N}^{+}(\mathrm{Me})_{2} \mathrm{CH}_{2} \mathrm{C}_{6} \mathrm{H}_{4} \mathrm{CH}_{2} \mathrm{~N}^{+}(\mathrm{Me})$ $\left(\mathrm{C}_{4} \mathrm{H}_{7} \mathrm{CH}_{2} \mathrm{OH}\right)$ 为封端剂合成了具有三维纳米尺寸的MOR. 然而这些纳米MOR的合成使用了结构复杂、价格昂贵的模板剂或表面 活性剂. 因此, 开发简便、经济的MOR纳米晶合成路线仍是一个巨大挑战.

本文通过在凝胶中添加少量四乙基氢氧化铵(TEAOH)和商业化表面活性剂, 在低温下采用一步水热法成功制备了20-50 nm 颗粒自组装的多级孔MOR (MOR-M), 这是多级孔MOR合成中无c轴优势生长的首例报道. 采用X射线衍射、X射线荧光光谱、扫 
描电镜、透射电镜、 $\mathrm{N}_{2}$ 物理吸附、核磁共振、热重及 $\mathrm{NH}_{3}$ 程序升温脱附等多种表征手段对合成样品的物理化学性质进行了研究. 考察了合成参数对产物形貌和孔结构的影响, 发现TEAOH的加入和较低的晶化温度是合成MOR-M的关键因素, 而表面活性剂的 作用则是进一步抑制晶粒的过度生长. 仅添加双季铵盐表面活性剂 $\mathrm{C}_{12-2-12}$ 时得到的为 $c$ 轴优势生长的纳米片状多级孔MOR. 与常 规MOR相比, MOR-M具有较短的扩散路径、较大的外比表面积和丰富的介孔结构, 在大分子苯和苯甲醇苄基化反应中表现出较 常规MOR和具有更长 $c$ 轴长度的纳米片状MOR更高的活性和目标产物选择性. 在二甲醚羰基化制备乙酸甲酯的反应中, MOR-M 亦表现出较高的活性及抗失活性能, 积碳速率显著下降.

关键词: 纳米晶组装; 丝光沸石; 四乙基氢氧化铵; 表面活性剂; 催化活性

收稿日期: 2015-07-16. 接受日期: 2015-07-18. 出版日期: 2015-11-20.

*通讯联系人. 电话: (0411)84379998; 传真: (0411)84379289; 电子信箱: liuzm@dicp.ac.cn

\#通讯联系人。电话: (0411)84379218; 传真: (0411)84379289; 电子信箱: tianpeng@dicp.ac.cn

基金来源：国家自然科学基金(21101150, 21476228, 21473182).

本文的英文电子版由Elsevier出版社在ScienceDirect上出版(http://www.sciencedirect.com/science/journal/18722067). 